\title{
Acoustic Resonance in Cylindrical Tubes with Side Branches
}

\author{
by John F. Schill
}

ARL-TR-6451

May 2013

Approved for public release; distribution unlimited. 


\section{NOTICES}

\section{Disclaimers}

The findings in this report are not to be construed as an official Department of the Army position unless so designated by other authorized documents.

Citation of manufacturer's or trade names does not constitute an official endorsement or approval of the use thereof.

Destroy this report when it is no longer needed. Do not return it to the originator. 


\title{
Army Research Laboratory
}

Adelphi, MD 20783-1197

ARL-TR-6451

May 2013

\section{Acoustic Resonance in Cylindrical Tubes with Side Branches}

\author{
John F. Schill \\ Sensors and Electron Devices Directorate, ARL
}




\begin{tabular}{|c|c|c|c|c|c|}
\hline \multicolumn{5}{|c|}{ REPORT DOCUMENTATION PAGE } & $\begin{array}{c}\text { Form Approved } \\
\text { OMB No. 0704-0188 }\end{array}$ \\
\hline \multicolumn{6}{|c|}{$\begin{array}{l}\text { Public reporting burden for this collection of information is estimated to average } 1 \text { hour per response, including the time for reviewing instructions, searching existing data sources, gathering and maintaining the } \\
\text { data needed, and completing and reviewing the collection information. Send comments regarding this burden estimate or any other aspect of this collection of information, including suggestions for reducing the } \\
\text { burden, to Department of Defense, Washington Headquarters Services, Directorate for Information Operations and Reports (0704-0188), } 1215 \text { Jefferson Davis Highway, Suite } 1204 \text {, Arlington, VA } 22202-4302 \text {. } \\
\text { Respondents should be aware that notwithstanding any other provision of law, no person shall be subject to any penalty for failing to comply with a collection of information if it does not display a currently } \\
\text { valid OMB control number. } \\
\text { PLEASE DO NOT RETURN YOUR FORM TO THE ABOVE ADDRESS. }\end{array}$} \\
\hline \multicolumn{2}{|c|}{$\begin{array}{l}\text { 1. REPORT DATE (DD-MM-YYYY) } \\
\text { May } 2013\end{array}$} & \multicolumn{3}{|c|}{$\begin{array}{l}\text { 2. REPORT TYPE } \\
\text { Final }\end{array}$} & 3. DATES COVERED (From - To) \\
\hline \multirow{3}{*}{\multicolumn{5}{|c|}{$\begin{array}{l}\text { 4. TITLE AND SUBTITLE } \\
\text { Acoustic Resonance in Cylindrical Tubes with Side Branches }\end{array}$}} & 5a. CONTRACT NUMBER \\
\hline & & & & & \\
\hline & & & & & 5b. GRANT NUMBER \\
\hline & & & & & 5c. PROGRAM ELEMENT NUMBER \\
\hline & & & & & 5e. TASK NUMBER \\
\hline & & & & & 5f. WORK UNIT NUMBER \\
\hline \multicolumn{5}{|c|}{$\begin{array}{l}\text { 7. PERFORMING ORGANIZATION NAME(S) AND ADDRESS(ES) } \\
\text { U.S. Army Research Laboratory } \\
\text { ATTN: RDRL-SEE-E } \\
\text { 2800 Powder Mill Road } \\
\text { Adelphi, MD 20783-1197 }\end{array}$} & $\begin{array}{l}\text { 8. PERFORMING ORGANIZATION } \\
\text { REPORT NUMBER } \\
\text { ARL-TR-6451 }\end{array}$ \\
\hline \multicolumn{5}{|c|}{ 9. SPONSORING/MONITORING AGENCY NAME(S) AND ADDRESS(ES) } & 10. SPONSOR/MONITOR'S ACRONYM(S) \\
\hline \multicolumn{6}{|c|}{ 12. DISTRIBUTION/AVAILABILITY STATEMENT } \\
\hline \multicolumn{6}{|c|}{ Approved for public release; distribution unlimited. } \\
\hline \multicolumn{6}{|c|}{ 13. SUPPLEMENTARY NOTES } \\
\hline \multicolumn{6}{|l|}{ 14. ABSTRACT } \\
\hline \multicolumn{6}{|c|}{$\begin{array}{l}\text { A study was done in order to understand the acoustic resonance of narrow cylindrical tubes with side branch holes that are } \\
\text { used in photo-acoustic spectrometers. A review of the available literature on the subject lead to an adaptation of electrical } \\
\text { transmission line matrix representation to determine the resonant frequencies of the tubes. Experiments were carried out on } \\
\text { PVC models of the actual tubes of the photo-acoustic spectrometer. The theory of acoustic resonance in cylindrical tubes with } \\
\text { side branch structures was used to calculate the resonant frequencies. These frequencies were compared to the experimental } \\
\text { results. }\end{array}$} \\
\hline \multicolumn{6}{|c|}{ 15. SUBJECT TERMS } \\
\hline \multicolumn{6}{|c|}{ Liquid nitrogen, evaporative spray cooling, heat transfer } \\
\hline \multicolumn{3}{|c|}{ 16. SECURITY CLASSIFICATION OF: } & $\begin{array}{l}\text { 17. LIMITATION } \\
\text { OF } \\
\text { ABSTRACT }\end{array}$ & $\begin{array}{l}\text { 18. NUMBER } \\
\text { OF } \\
\text { PAGES }\end{array}$ & $\begin{array}{l}\text { 19a. NAME OF RESPONSIBLE PERSON } \\
\text { John F. Schill }\end{array}$ \\
\hline $\begin{array}{l}\text { a. REPORT } \\
\text { Unclassified }\end{array}$ & $\begin{array}{l}\text { b. ABSTRACT } \\
\text { Unclassified }\end{array}$ & $\begin{array}{l}\text { c. THIS PAGE } \\
\text { Unclassified }\end{array}$ & UU & 30 & $\begin{array}{l}\text { 19b. TELEPHONE NUMBER (Include area code) } \\
\text { (301) 394-1995 }\end{array}$ \\
\hline
\end{tabular}




\section{Contents}

List of Figures $\quad$ iv

List of Tables $\quad$ iv

$\begin{array}{lr}\text { 1. Introduction } & 1\end{array}$

2. Acoustic Waves in Cylindrical Tubes $\quad 1$

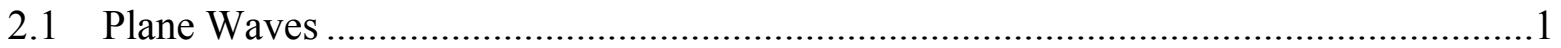

2.2 Higher Order Modes............................................................................................

3. Transmission Line Theory Applied to Acoustics $\quad 8$

4. Musical Instrument Design $\quad 11$

5. Mason’s Approximate Network Acoustic Filter $\quad 14$

6. Experimental Results and Analysis $\quad 15$

$\begin{array}{ll}\text { 7. Conclusions } & 20\end{array}$

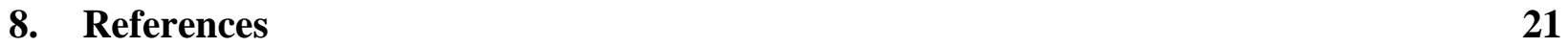

$\begin{array}{ll}\text { List of Symbols, Abbreviations, and Acronyms } & 22\end{array}$

$\begin{array}{ll}\text { Distribution List } & 24\end{array}$ 


\section{List of Figures}

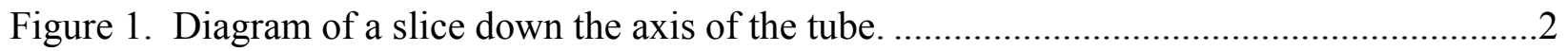

Figure 2. Geometry of a tube in cylindrical coordinates. ....................................................5

Figure 3. A transmission line with source and load..........................................................

Figure 4. An infinitely small segment of the transmission line. ............................................9

Figure 5. Tube with no holes. ........................................................................................ 12

Figure 6. Model of tube with singe side branch................................................................ 12

Figure 7. Mason's representation of an acoustic filter as an electronic network........................14

Figure 8. Mason's equivalent for side branch representation..............................................15

Figure 9. Picture of experimental setup for tube with a single side branch..............................16

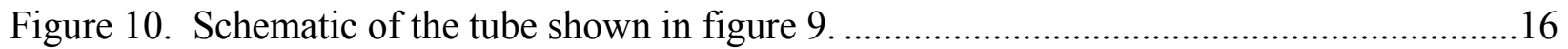

Figure 11. Picture of the tube used for varying the diameter of the side branch.......................18

Figure 12. Diagram of actual acousto-optic spectrometer................................................... 19

Figure 13. Structure of side branch with two sections.........................................................19

\section{List of Tables}

Table 1. Result of measuring the resonant frequency of tubes with side branches of various

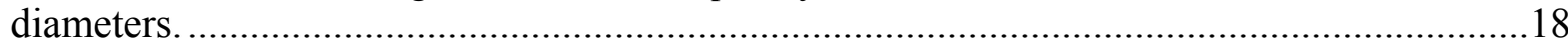




\section{Introduction}

In order to make the photo-acoustic spectrometer used for the detection of energetics more efficient, it is important to understand the acoustic resonance conditions in the photo-acoustic cell. At first glance this may seem simple, but as it turns out the interaction of the main tube with side branches is quite complicated. Assuming that a hole is made exactly in the middle of the main tube, the length and diameter of the side branch will determine the resonant frequency. This can be anywhere between the resonance of the main tube and twice that frequency. Starting as early as 1922 and continuing through the present day, researchers, such as Mason (1) at Bell Labs have studied the acoustics of tubes and tried to develop techniques that would predict the resonant or filtering characteristics of tubes with side branches.

As long ago as the Golden Age of Greece, man has been able to place holes in the correct position along a hollow tube to make music. Today instrument designers have developed a mathematical technique to determine the location and shape of the holes along the tube.

A more modern approach, which is an extension of Mason's use of electrical network theory applied to acoustics, is the use of electrical transmission line theory to describe the tube and the side branch as matrices. The resultant matrix is then applied to the pressure and mass flow at any point along the tube in order to calculate the pressure and mass flow at any other point. Here, pressure and mass flow are synonymous with voltage and current.

In this report, I will discuss both musical instrument design and matrix theory that is applied to acoustic tubes with side branches. I will also discuss a series of experiments performed on tubes with side branch holes of various sizes and shapes. I will then apply the theory to our photoacoustic spectrometer to show that the theory predicts the resonant frequency within a few percent. In closing, I will discuss several sources of error in these methods.

\section{Acoustic Waves in Cylindrical Tubes}

\subsection{Plane Waves}

Acoustic waves that are confined to a tube with rigid walls can be considered to be plane waves, assuming the diameter of the tube is small compared to the wave length of the acoustic wave. Higher order modes are only possible when the diameter of the tube is greater than two-thirds of the wave length (2). Also, the plane wave approximation only holds for frequencies where the effects of viscose friction are negligible. At higher frequencies, the effect of viscosity is confined to a thin layer that is close to the wall $\left(\delta_{a}=\left(\frac{2 v}{\omega}\right)^{1 / 2}\right)$, where $v=\eta / \rho$ is the kinetic viscosity. In 
order to make the plane wave approximation valid, one should have a boundary layer that is thin: $\frac{\delta_{a}}{d} \ll 1$ (where $d$ is the diameter of the tube). This leads to the following relationship (2): $\frac{2 v}{\pi d^{2}} \ll f<\frac{c}{2 d}$. The kinetic viscosity of air is $1.5 \times 10^{-5} \mathrm{~m}^{2} / \mathrm{s}$, so for a representative tube with 1 $\mathrm{mm}$ diameter, the plane wave approximation is valid for frequencies $9.5 \mathrm{~Hz}<\mathrm{f}<170 \mathrm{kHz}$.

When acoustic waves propagate (alternating compression and expansion of the medium), the temperature gradients between these compressed and expanded volumes are very small. Because of this, very little heat flows from one region to another, and the process can be considered adiabatic. In an adiabatic process, the pressure in the tube can be represented as a function of density, $P=P(\rho)$. Now from the ideal gas law $P V=n R T$, and for an adiabatic process, this leads to $P=C \rho^{\gamma}$, where $C$ is a constant and $\gamma$ is the ratio of the specific heats. If we now represent the function $P(\rho)$ as a Taylor series expansion around the point $\rho_{0}$ and discard higher order terms we have

$$
P-P_{0}=\left(\frac{\partial P}{\partial \rho}\right)\left(\rho-\rho_{0}\right) .
$$

In the limit, this can be expressed as

$$
d P=\left(\frac{d P}{d \rho}\right)_{0} d \rho
$$

where $\left(\frac{d P}{d \rho}\right)_{0}$ is the slope of the adiabatic plot of pressure vs. density at the point $\left(P_{0, \rho_{0}}\right)$.

Acoustic waves are longitudinal waves. This means that particles move back and forth in the direction of propagation, creating alternating volumes of compression and expansion. The restoring force that propagates the wave along is simply the elastic opposition that arises when the fluid is compressed.

Figure 1 below will be used to derive an acoustic plane wave equation. The variables to be used in this derivation are listed and defined below the figure. This derivation follows the discussion given by Kinsler and Frey (3).

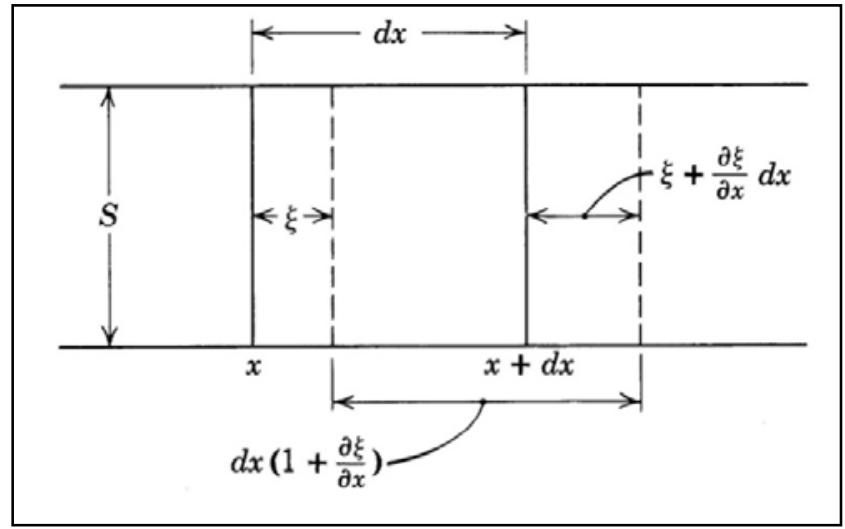

Figure 1. Diagram of a slice down the axis of the tube. 
The variables to be used in this derivation are listed and defined below:

$x=$ equilibrium coordinate of a thin sheet of molecules

$\xi=$ displacement of the sheet along the axis of propagation

$u=$ velocity of the sheet $u=\frac{\partial \xi}{\partial t}$

$\rho=$ instantaneous density at any point

$\rho_{0}=$ constant equilibrium density of the medium

$s=$ condensation at any point defined below

$$
s=\frac{\rho-\rho_{0}}{\rho_{0}} \text { or } \rho=\rho_{0}(1+s) .
$$

$P=$ instantaneous pressure at any point

$P_{0}=$ constant equilibrium pressure

$p=$ excess pressure or acoustic pressure at any point defined as $p=P-P_{0}$

$c=$ velocity of wave propagation

First, we must address the conservation of mass. The mass contained between $x$ and $x+d x$ can be written as $\rho_{0} S d x$, where $S d x$ is the volume element. After an acoustic wave passes, the particles at $x$ will have moved to $x+\xi$, and the particles at $x+d x$ will have moved to $x+d x+(\xi+d \xi)$, so that the new volume is $S d x\left(1+\frac{\partial \xi}{\partial x}\right)$. The mass within this volume must be the same as the original mass due to the conservation of mass, which leads to the following:

$$
\rho S d x\left(1+\frac{\partial \xi}{\partial x}\right)=\rho_{0} S d x .
$$

Now, if we replace $\rho$ with $\rho_{0}(1+s)$ from equation 3, equation 4 becomes

$$
(1+s)\left(1+\frac{\partial \xi}{\partial x}\right)=1 .
$$

Because both the density and molecular displacements are very small (for even load noises neither will exceed $10^{-4}$ ), we can neglect the product of $\mathrm{s} \frac{\partial \xi}{\partial x}$, and equation 5 becomes

$$
s=-\frac{\partial \xi}{\partial x}
$$

For acoustic waves, the incremental pressure changes are very small, so that $d P$ can be replaced by $p$ the acoustic pressure, and the small change in density $d \rho$ can be replaced by $s \rho_{0}$ (see equation 3). Now, using these in equation 2 leads to

$$
p=\left(\frac{d P}{d \rho}\right)_{0} \rho_{0} s
$$


We can also let

$$
c^{2}=\left(\frac{d P}{d \rho}\right)_{0}
$$

so that we have

$$
p=\rho_{0} \mathrm{c}^{2} \mathrm{~s}
$$

Finally, by replacing $s$ with $-\frac{\partial \xi}{\partial x}$ from equation 6 , we have

$$
p=-\rho_{0} c^{2} \frac{\partial \xi}{\partial x}
$$

When a fluid is deformed, as we have described, the pressure acting on the two faces of the volume element $S d x$ is slightly different, producing a net force in the positive $x$ direction.

Because the external force acting on each face is equal to the pressure times the area, the net force can be written as

$$
d F_{\mathrm{x}}=\left[p-\left(p+\frac{\partial \xi}{\partial x} d x\right)\right] S=-\frac{\partial \rho}{\partial x} d x S
$$

Now, if we set this net force equal to the mass of the volume element times its acceleration, we are left with

$$
-\frac{\partial p}{\partial x}=\rho_{0} \frac{\partial^{2} \xi}{\partial t^{2}}
$$

Differentiating equation 10 with respect to $x$ and replacing $\frac{\partial p}{\partial x}$ in equation 12 , we are left with

$$
\frac{\partial^{2} \xi}{\partial t^{2}}=c^{2} \frac{\partial^{2} \xi}{\partial x^{2}}
$$

This is the wave equation in displacement, and similar equations apply to pressure, velocity, and condensation.

A note here should be added in regard to the wave velocity in a tube. In air, the velocity is a function of temperature alone and is given by

$$
c=331.3+.606 T\left({ }^{0} C\right) \frac{m}{s} .
$$

At $20{ }^{\circ} \mathrm{C}$, this leads to a velocity, $c=343.6 \frac{\mathrm{m}}{\mathrm{s}}$. This velocity is no longer valid inside a tube with rigid walls due to the thermal exchange with the walls and viscous friction at the walls. The first to study the velocity and attenuation of sound waves in tubes was Helmholtz (4) in 1863. Later, Kirchhoff (5) and Rayleigh (6) extended this theory. Zwikker and Kosten (7) offered the most widely accepted equation for the propagation constant derived from Kirchhoff's work: 


$$
\Gamma=\sqrt{\frac{J_{0}\left(\mathrm{i}^{3 / 2} S\right)}{J_{2}\left(\mathrm{i}^{3 / 2} S\right)}} \sqrt{\gamma+(\gamma-1) \frac{J_{2}\left(\mathrm{i}^{3 / 2} \sqrt{\sigma} S\right)}{J_{0}\left(\mathrm{i}^{3 / 2} \sqrt{\sigma} S\right)}},
$$

Where $J_{n}$ are the Bessel functions of order $n ; S=r \sqrt{\frac{\omega}{v}}$ is the shear wave number; $r$ is the inner radius of the tube; $\omega$ is the radian frequency; the parameter $\sqrt{\sigma} S$ is the ratio of the radius $r$ to the thermal boundary layer defined earlier as $\left(\delta_{a}=\left(\frac{2 v}{\omega}\right)^{1 / 2}\right)$, where $v=\eta / \rho$ the kinetic viscosity; and $\gamma=\frac{C_{p}}{C_{V}}$ is the ratio of the specific heats. Now, the important thing to take away here is that the phase velocity is given by

$$
v_{p}=\frac{c}{\operatorname{Im}(\Gamma)} .
$$

Tijdeman (8) did a numerical analysis of this equation and published the result in tables based on $S$ and $k$; the reduced frequency given by $k=\frac{\omega r}{c}$. For our representative cell, with $1 \mathrm{~mm}$ diameter and $10 \mathrm{~mm}$ length, $S=44$ and $k=0.1691$. From the tables, the $\operatorname{Im}(\Gamma)=1.0261$ and the velocity in the tube is $335 \mathrm{~m} / \mathrm{s}$.

\subsection{Higher Order Modes $(9,10,11)$}

Figure 2 depicts a section of a cylindrical tube with radius $r=a$. It is assumed that the tube walls are perfectly rigid and smooth. Wave propagation is along the positive $z$ axis into the report. We find that the acoustic pressure in the tube is governed by the wave equation:

$$
\nabla^{2} p(r, \varphi, z, t)-\frac{1}{c^{2}} \frac{\partial^{2}}{\partial t^{2}} p(r, \varphi, z, t)=0 .
$$

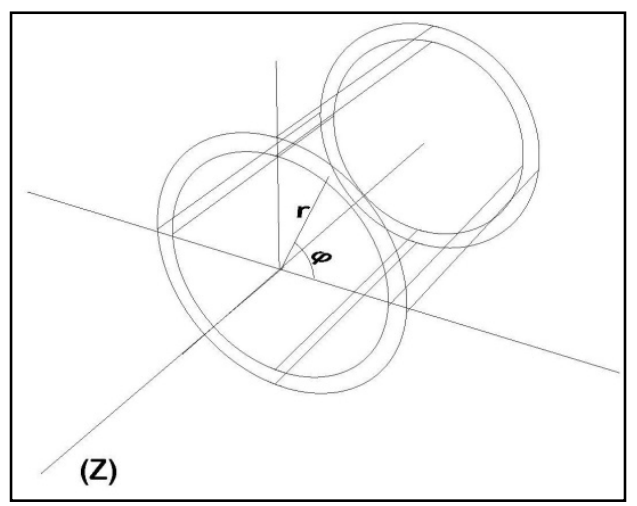

Figure 2. Geometry of a tube in cylindrical coordinates.

We can use the technique of the separation of variables to solve this differential equation by allowing

$$
p(r, \varphi, z, t)=R(r) \Phi(\varphi) Z(z) T(t) .
$$


The Laplace operator in cylindrical coordinates is defined as

$$
\nabla^{2} \equiv\left(\frac{\partial^{2}}{\partial r^{2}}+\frac{1}{r} \frac{\partial}{\partial r}+\frac{1}{r^{2}} \frac{\partial^{2}}{\partial \varphi^{2}}+\frac{\partial}{\partial z^{2}}\right)
$$

If we now insert equation 18 into equation 17 and apply the Laplace operator, we are left with the following after dividing through by $p(r, \varphi, z, t)$ :

$$
\frac{R^{\prime \prime}(r)}{R(r)}+\frac{1}{r} \frac{R^{\prime}(r)}{R(r)}+\frac{1}{r^{2}} \frac{\Phi^{\prime \prime}(\varphi)}{\Phi(\varphi)}+\frac{Z^{\prime \prime}(z)}{Z(z)}-\frac{1}{c^{2}} \frac{T^{\prime \prime}(t)}{T(t)}=0
$$

In order to proceed with the solution of equation 20 , move the term exclusive in $t$ to the righthand side of equation 20. Noticing that the right-hand side is a function of $t$ alone, it must, therefore, be equal to a constant. Allowing that constant to be equal to $-k^{2}$, where $k=\frac{\omega}{c}$; we are led to the following equation:

$$
T^{\prime \prime}(t)+\omega^{2} T(t)=0
$$

This equation is that of a harmonic oscillator, and its solution is of the form

$$
T(t)=T_{0} e^{ \pm j \omega t}
$$

Now, we address the term in $z$. We can move the term in $z$ to the right side of equation 20 so that now the right side of equation 20 is a term in $z$ alone. The right side again must be equal to a constant as follows:

$$
-k^{2}-\frac{Z "(z)}{Z(z)}=-\sigma_{c}^{2}
$$

This can be rearranged as

$$
Z^{\prime \prime}(z)+\left(k^{2}-\sigma_{c}^{2}\right) Z(z)=0 .
$$

The solution of this equation will be of the form

$$
Z(z)=Z_{0} e^{ \pm j \beta z}
$$

Here, $\beta^{2}=k^{2}-\sigma_{c}^{2}$. It should be noted that when $k^{2}>\sigma_{c}^{2}$, the solution is oscillatory; when $k^{2}<\sigma_{c}^{2}$, the solution is exponentially growing or decaying; and when $k^{2}=\sigma_{c}^{2}$, the solution is constant. By convention, we will choose $k^{2}>\sigma_{c}^{2}$, and if we choose propagation in the positive $z$ direction, we can drop the + sign from the exponent.

Equation 20 can now be written in the form

$$
\frac{r^{2}}{R} \frac{d^{2} R}{d r^{2}}+\frac{r}{R} \frac{d R}{d r}+r^{2} \sigma_{c}^{2}=\frac{-1}{\Phi} \frac{d^{2} \Phi}{d \varphi^{2}}
$$

and because we have two completely independent equations in different variables equal to each other, they must both be equal to the same constant so that 


$$
\begin{gathered}
\frac{-1}{\Phi} \frac{d^{2} \Phi}{d \Phi^{2}}=\sigma_{\varphi}^{2}, \\
\frac{d^{2} \Phi}{d \varphi^{2}}+\sigma_{\varphi}^{2} \Phi=0, \\
\text { or } \begin{array}{c}
r^{2} \frac{d^{2} R}{d r^{2}}+r \frac{d R}{d r}+\left(r^{2} \sigma_{c}^{2}-\sigma_{\varphi}^{2}\right) R=0 .
\end{array}
\end{gathered}
$$

The solution to equation 27 is

$$
\Phi(\varphi)=a_{0} \sin \left(\sigma_{\varphi} \varphi\right)+b_{0} \cos \left(\sigma_{\varphi} \varphi\right)
$$

and $\Phi(\varphi)$ must be periodic in $\varphi$ or $\Phi(\varphi)=\Phi(\varphi \pm m 2 \pi)$, so that $\sigma_{\varphi}$ must be an integer $\mathrm{n}=1,2,3 \ldots$ :

$$
\Phi(\varphi)=a_{0} \sin (n \varphi)+b_{0} \cos (n \varphi) .
$$

Now, equation 28 is Bessel's differential equation. Solutions to this equation take the form of

$$
R(r)=C J_{n}\left(\sigma_{c} r\right)+D Y_{n}\left(\sigma_{c} r\right)
$$

where $J_{n}$ and $Y_{n}$ are the Bessel functions of the first and second kind in order $n$, respectively. There are two boundary conditions that must be met. First, the function $p(r, \varphi, z, t)$ must be bounded everywhere within the tube. Because the Bessel function of the second kind approaches $-\infty$ as $r \rightarrow 0$, we must set $D=0$. The second boundary condition is as follows. Because the wall of the tube is perfectly rigid, there can be no net flow in the direction of $r$ at the wall $r=a$ :

$$
\frac{\partial p}{\partial r}=0 \quad \text { at } \quad r=a
$$

We can now state the complete solution of the wave equation for $p(r, \varphi, z, t)$ :

$$
p(r, \varphi, x, t)=(\mathrm{A} \sin (n \varphi)+\mathrm{B} \cos (n \varphi)) J_{n}\left(\sigma_{c} r\right) \exp [j(-\beta z+\omega t)]
$$

where the constants $\mathrm{C}, Z_{0}$, and $T_{0}$ have been incorporated into $\mathrm{A}$ and $\mathrm{B}$. The boundary condition at $r=a$ leads to $J_{n}^{\prime}\left(\sigma_{c} a\right)=0$. After looking up the roots of the first derivative $J_{n}^{\prime}\left(\sigma_{c} a\right)=0$, we find that $\sigma_{\mathrm{c}} a=1.84118$ for the first propagating none 0,0 mode of the lowest order. Because $\sigma_{\mathrm{c}}=$ $2 \pi / \lambda_{\mathrm{c}}$ and $\lambda_{\mathrm{c}}=c / f_{c}$, where $c$ is the velocity of sound, and $f_{c}$ is the cutoff frequency:

or

$$
1.84118=2 \pi a / \lambda_{c}=2 \pi a f_{c} / c
$$

If we apply this to a representative tube with $1 \mathrm{~mm}$ diameter, and we assume an approximate velocity of $340 \mathrm{~m} / \mathrm{s} f_{c} \cong 200 \mathrm{kHz}$, this indicates that any wave of frequency less than $200 \mathrm{kHz}$ will propagate as a plane wave. 


\section{Transmission Line Theory Applied to Acoustics}

It turns out that a duct with an acoustic wave propagating within can be modeled as if it was an electrical transmission line. In all that will follow, this analogy will be useful. The analogous terms are pressure with voltage and mass flow with current. Acoustic impedance will be defined as pressure/mass flow $\left(Z=\frac{p}{U}=\frac{\rho_{0} C}{S}\right)$, and admittance is defined as $\frac{1}{z}$. The density of the gas is $\rho_{0}$, $c$ is the speed of sound in the medium, and $S$ is the cross-sectional area of the tube. Expanding on the transmission line analogy, distributed inertance $(M)$ and distributed compliance $(C)$ are associated with inductance and capacitance, respectively. As in a transmission line, the characteristic impedance is given by (12)

$$
Z_{0}=\sqrt{\frac{L}{C}}=\sqrt{\frac{M}{C}}=\sqrt{\frac{\rho_{0} / S}{S / \rho_{0} c^{2}}}=\frac{\rho_{0} c}{S},
$$

where $M=\frac{\rho_{0}}{S}$ and $C=\frac{S}{\rho_{0} c^{2}}$.

Now let's begin the analysis of a transmission line using figure 3 as our model.

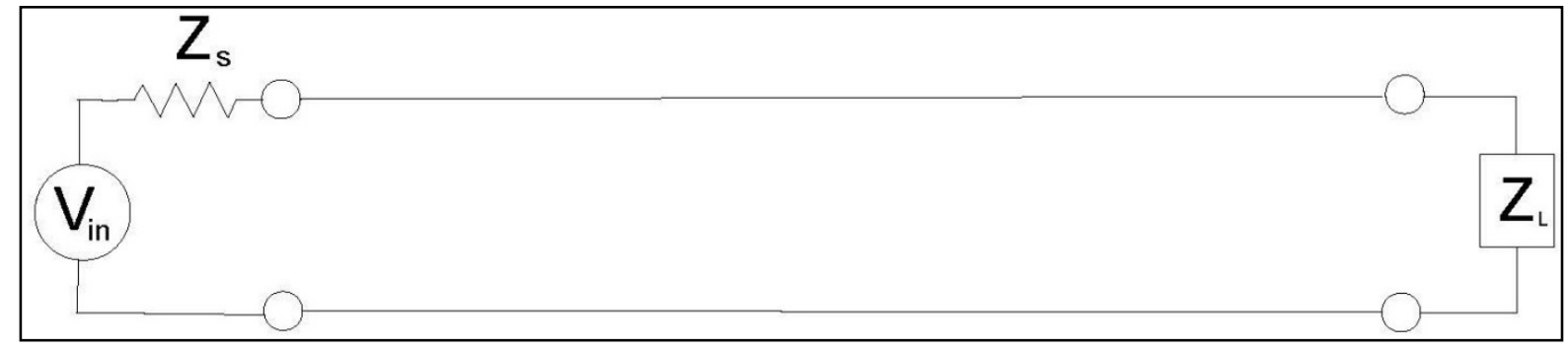

Figure 3. A transmission line with source and load.

A transmission line is different than an ordinary electrical circuit, because its components are distributed along the line and not lumped into resistors and capacitors. It turns out that if the load impedance is not the same as the characteristic impedance, there will be a reflected wave traveling back toward the source due to the conservation of energy at the load. In this case, that direction is left. It also turns out that the impedance changes along the line. This is due to the load impedance having a differing effect at different positions along the line. This is analogous to the way the load on the secondary of a transformer is seen by the primary due to mutual inductance or coupling between the two sides:

$$
Z(z)=\frac{V(z)}{I(z)}
$$

To develop an equation for the impedance along the line and the input impedance seen by the source, we have to look at the superposition of the forward and reverse voltage and current: 


$$
\begin{gathered}
V(z)=V_{+} e^{-j k z}+V_{-} e^{j k z}, \\
I(z)=Y_{0}\left(V_{+} e^{-j k z}-V_{-} e^{j k z}\right) .
\end{gathered}
$$

Here, $Y_{0}$ is the admittance into the transmission line $\left(Y_{0}=1 / Z\right), V_{+}$is the wave traveling right, and $V$. is that traveling left. Figure 4 shows a segment of the transmission line. If we apply Kirchhoff's voltage law around this loop, we have

$$
V-j \omega L I(z) d z-(V+d V)=0,
$$

from which we have

$$
\frac{d V}{d z}=-j \omega L I(z) \text {. }
$$

Using the fact that

$$
k=\omega \sqrt{L C},
$$

and applying equation 40 to equation 37 , we are left with equation 38 .

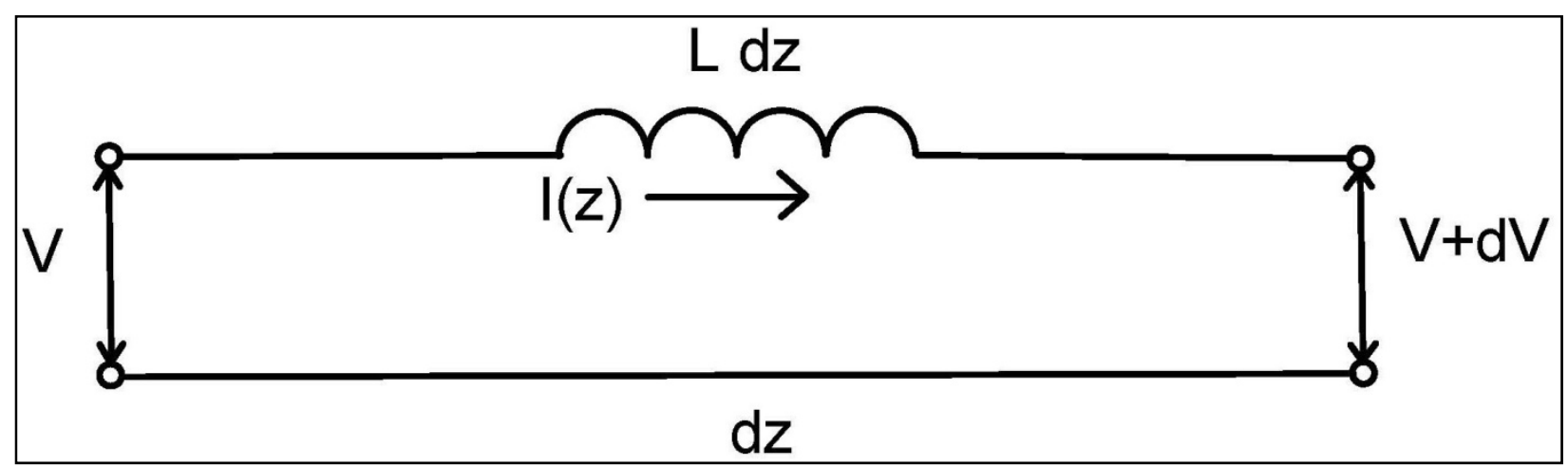

Figure 4. An infinitely small segment of the transmission line.

Now, to develop an expression for the impedance as a function of position on the line, we need a couple of items. First, $Z_{L}=V(z=l) / I(z=l)$. Then we need to define a reflection coefficient $\Gamma_{L}=V$. $/ V_{+}$. If we apply these to equation 37 divided by equation 38 and let the load be at $z=0$ we have

$$
\frac{V_{+}+V_{-}}{I_{+}-I_{-}}=\frac{V_{+}+\Gamma_{L} V_{+}}{V_{+}-\Gamma_{L} V_{+}} Z_{0}=\frac{1+\Gamma_{L}}{1-\Gamma_{L}} Z_{0}=Z_{L} .
$$

Solving this for $\Gamma_{L}$ we have

$$
\begin{gathered}
\Gamma_{L}=\frac{Z_{L}-Z_{0}}{Z_{0}+Z_{L}}, \\
Z(z)=\frac{V(z)}{I(z)}=\frac{V_{+} e^{-j k z}+\Gamma_{L} V_{+} e^{j k z}}{\frac{1}{Z_{0}}\left(V_{+} e^{-j k z}-\Gamma_{L} V_{+} e^{j k z}\right)}, \\
Z(z)=Z_{0} \frac{\left(Z_{0}+Z_{L}\right) e^{-j k z}+\left(Z_{L}-Z_{0}\right) e^{j k z}}{\left(Z_{0}+Z_{L}\right) e^{-j k z}-\left(Z_{L}-Z_{0}\right) e^{j k z}}
\end{gathered}
$$




$$
\mathrm{Z}(\mathrm{z})=\mathrm{Z}_{0} \frac{\mathrm{Z}_{\mathrm{L}} \cos (\mathrm{kz})-\mathrm{j} \mathrm{Z}_{0} \sin (\mathrm{kz})}{\mathrm{Z}_{0} \cos (\mathrm{kz})-\mathrm{j} \mathrm{Z}_{\mathrm{L}} \sin (\mathrm{kz})}
$$

Letting the position of the source be $z=-l$, we are left with the important result

$$
Z_{\text {in }}=Z_{0} \frac{Z_{L}+j Z_{0} \tan (k l)}{Z_{0}+j Z_{L} \tan (k l)}
$$

This equation will be used repeatedly, as we develop the equations for resonance in our tube.

Now we apply a very powerful matrix representation to our transmission line problem. We want to develop a technique that will allow us to transform a voltage and current at any point along the line to a voltage and current at a different point on the line:

$$
\left|\begin{array}{l}
V_{2} \\
I_{2}
\end{array}\right|=\left|\begin{array}{ll}
A & B \\
C & D
\end{array}\right|\left|\begin{array}{c}
V_{1} \\
I_{1}
\end{array}\right| \text {. }
$$

Let's be reminded of equations 37 and 38, and we will let position 1 be at $z=0$ (the load) and position 2 be at $z=-l$ (the source) as we have discussed before:

$$
\begin{gathered}
V(z)=V_{+}\left(e^{-j k z}+\Gamma_{L} e^{j k z}\right), \\
I(z)=Y_{0} V_{+}\left(e^{-j k z}-\Gamma_{L} e^{j k z}\right) .
\end{gathered}
$$

Now let's let the load be an open so that $\Gamma_{L}=+1$ and $V(z=0)=+2 V_{+}$applying these to equations 45,46 , and 47 we have

$$
\begin{aligned}
& V(z=-l)=V_{+}\left(e^{j k l}+e^{-j k l}\right)=2 A V_{+}, \\
& I(z=-l)=\frac{V_{+}}{z_{0}}\left(e^{j k l}-e^{-j k l}\right)=2 C V_{+} .
\end{aligned}
$$

These lead to

$$
\begin{gathered}
A=\cos k l, \\
\mathrm{C}=\frac{j}{z_{0}} \sin k l .
\end{gathered}
$$

Conversely, if we let the load be a short so that $\Gamma_{L}=-1$ and $I(z=0)=\frac{2}{z_{0}} V_{+}$and $V(z=0)=0$ again, using equations 45,46 , and 47 we have

$$
\begin{aligned}
& V(z=-l)=V_{+}\left(e^{j k l}-e^{-j k l}\right)=\frac{2}{Z_{0}} V_{+} B, \\
& \mathrm{I}(z=-l)=\frac{V_{+}}{z_{0}}\left(e^{j k l}+e^{-j k l}\right)=\frac{2}{Z_{0}} V_{+} D,
\end{aligned}
$$

leading to

$$
B=j Z_{0} \sin k l
$$




$$
D=\cos k l .
$$

So, we now have the transfer matrix from point 1 to point 2 , where $l$ represents the length of that section of the line, and $Z_{0}$ is the characteristic impedance in that section.

We can extend this technique to handle a line with any number of sections in the following manner. We define the transfer matrix as follows:

$$
T_{i}=\left|\begin{array}{cc}
\cos k_{i} l_{i} & j Z_{0 i} \sin k_{i} l_{i} \\
\frac{j}{Z_{0 i}} \sin k_{i} l_{i} & \cos k_{i} l_{i}
\end{array}\right|,
$$

and we use this to describe a line with $N$ sections as follows:

$$
\left|\begin{array}{c}
V_{S} \\
I_{S}
\end{array}\right|=T_{N} \cdot T_{N-1} \cdots T_{1}\left|\begin{array}{c}
V_{L} \\
I_{L}
\end{array}\right| .
$$

This will become useful later when we describe acoustic tubes with side branches and tubes that change diameter.

\section{Musical Instrument Design}

A flute is essentially a hollow tube with a way at one end to modulate the pressure of the air column within the tube. Along the length of the tube are holes that essentially change the length of the tube, and, thereby, change the frequency of resonance in the tube. We will start with a tube with no holes as shown in figure 5. At resonance in the fundamental mode a differential pressure standing wave is established in the tube that has the greatest magnitude in the center of the tube and falls to zero at the ends. Higher order plane wave modes do propagate, and these will always be an integral number of half-wave lengths. Note that the effective length of the bore is always longer than the actual physical dimension of the tube. This is because the pressure wave penetrates a short distance beyond the end of the tube before partially reflecting back into the tube. I will state here without discussion that this correction is $0.3 D_{\text {bore }}(3,13,14)$. So that the effective length of the tube is $L_{\text {eff bore }}=L_{\text {bore }}+0.6 D_{\text {bore }}$ and the wave lengths of the resonant modes are given by $n \lambda=2 L_{\text {eff bore }}$, where $n$ is an integer $(1,2,3, \ldots)$. 


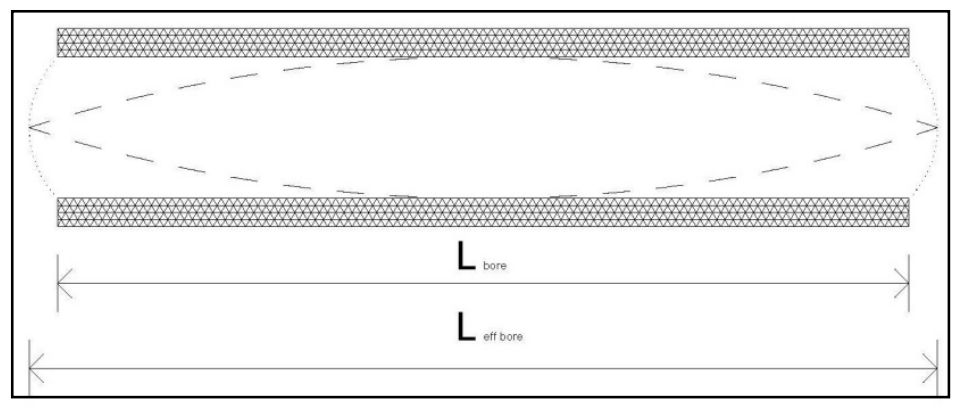

Figure 5. Tube with no holes.

The addition of a side branch effectively changes the length of the tube, so in a flute when one of the tone holes is opened the sound pitch becomes higher because the effective length of the tube has been shortened. In what follows, I will discuss the effect of a single tone hole, or side branch, on the resonant frequency of the tube. Figure 6 will be used in the discussion that follows, which is based on that of Nederveen (14).

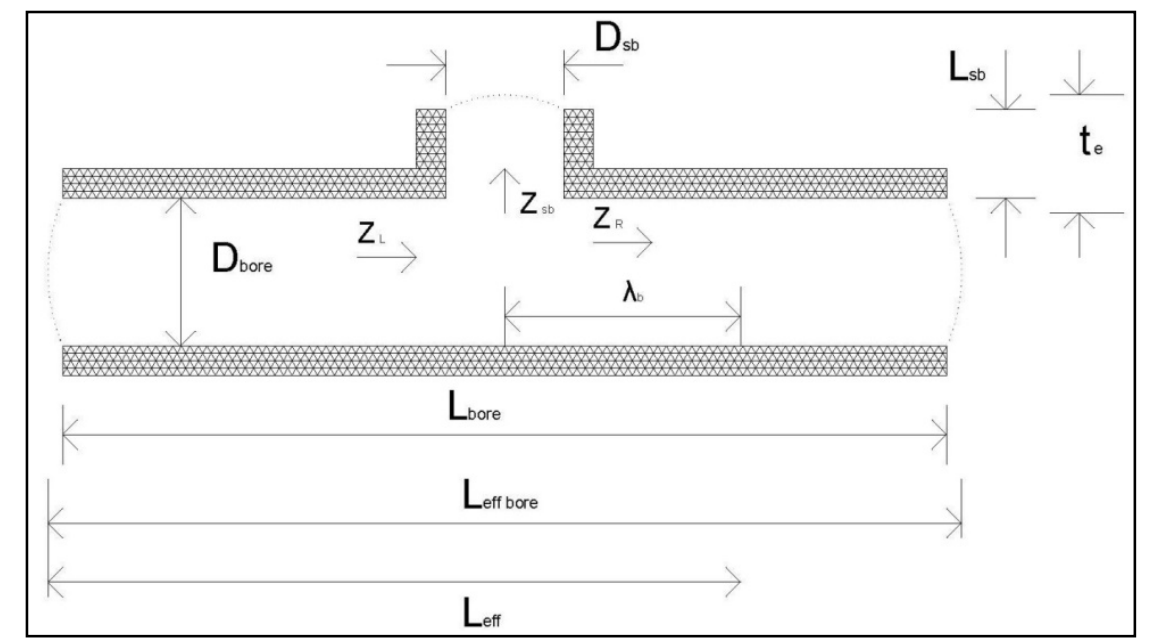

Figure 6. Model of tube with singe side branch.

As discussed in section 3, an acoustic tube can be modeled as if it is an electrical transmission line. The characteristic impedance $\left(Z_{0}\right)$ is equal to $p / U$, the differential pressure (or acoustic pressure) divided by the mass flow associated with the particle movement as the wave passes. Now applying Kirchhoff's current law at the junction, where the main tube meets the side branch, we see that the current into the junction must equal the current out of the junction. Because the pressure for all three branches must be equal, this leads to

$$
\frac{1}{Z_{L}}=\frac{1}{Z_{s b}}+\frac{1}{Z_{R}}
$$

or the admittance looking back down the bore from the side branch must equal the sum of the two admittances at the junction. Now, if we return to equation 44, we can describe the input 
impedance to any one of these sections by first setting $Z_{L}=0$, because all of our tube ends are open, and acoustic pressure there must go toward zero. We are left with the following:

$$
Z_{\text {in }}=j Z_{0} \tan k l \text {. }
$$

We are going to use this expression many times with modifications for the length of the tube being described and the characteristic impedance in that tube.

Now the concept of a replacement tube (14) needs to be introduced. The replacement tube is a fictitious tube that will represent the resonant tube after the correction for the side branch is introduced. The length of this fictitious tube is $L_{e f f}=\frac{L_{e f f} \text { bore }}{2}+\lambda_{b}$. Here, $\lambda_{b}$ will represent the corrected length of the side branch $t_{e}$ adjusted to represent the side branch as if it were in the main tube by correcting for the different areas:

$$
\lambda_{b}=t_{e}\left(\frac{D_{b o r e}}{D_{s b}}\right)^{2}
$$

Referring to the expression given at the beginning of section 3 for the characteristic impedance of any tube and equation 58, we can express the general admittance into a tube as follows:

$$
Y=\frac{1}{Z}=-\left(\frac{s}{j \rho_{0} c}\right) \cot (k Z+\psi) \text {. }
$$

Here, $S$ is the cross-sectional area of the tube, and $\psi$ is a phase introduced to handle any phase adjustment needed. Now, in order to describe the admittance of the side branch, we first see that at $z=0, Y \rightarrow \infty$, and this implies that $\psi=0$, so that at $z=-t_{e}$ :

$$
Y_{s b}=\left(\frac{S_{s b}}{j \rho_{0} c}\right) \cot k t_{e} .
$$

The admittance looking down the tube toward the load end is found in a similar manner:

$$
Y_{R}=\left(\frac{S_{\text {bore }}}{j \rho_{0} c}\right) \cot k \frac{L_{\text {eff bore }}}{2} .
$$

Now, to develop an expression for the admittance looking toward the source from the side branch, we first notice that at resonance, the impedance at the input goes to zero, so that $Y \rightarrow \infty$. Allowing $z=0$ at the source, this leads to $\psi=-m \pi$, where $m$ is an integer. Now, again looking at the resonance condition for the replacement tube, we have $k L_{\text {eff }}=m \pi$. This leads to the following at $z=-\frac{L_{\text {eff bore }} \text { : }}{2}$

$$
Y_{L}=-\left(\frac{S_{\text {bore }}}{j \rho_{0} c}\right) \cot \left(k \frac{L_{\text {eff bore }}}{2}-k L_{e f f}\right)
$$

Now, we can develop a first approximation for $\lambda_{b}$, which will be used in describing the experimental results to follow. Again from equation 57 we have

$$
Y_{L}=Y_{s b}+Y_{R}
$$


We now utilize the series expansion of the $\cot (x)=\frac{1}{x}$, because for our approximation we drop all the terms after the first. Inserting equations 61, 62, and 63 into 64, we are left with equation 57 after simplification:

$$
\frac{1}{\frac{L_{e f f \text { bore }}}{2}}+\frac{1}{\frac{L_{\text {eff bore }}}{2}-L_{\text {eff }}}+\frac{1}{t_{e} \frac{S_{\text {bore }}}{S_{s b}}}=0 .
$$

Now, we can let $\lambda_{b}$ represent the length of the side branch as it would appear in the main tube having the same admittance of the actual side branch:

$$
\lambda_{b}=t_{e} \frac{s_{\text {bore }}}{S_{s b}} .
$$

The length of the replacement tube used to describe the resonant tube of length $L_{e f f}$ will then given by

$$
L_{e f f}=\frac{L_{e f f \text { bore }}}{2}+\lambda_{b}
$$

\section{Mason's Approximate Network Acoustic Filter}

It seems that Stewart $(15,16)$ was the first to describe an acoustic filter by using electrical network theory in 1922. Mason (1) showed in 1927 that this theory was good only as a first approximation, and that some additions had to be made. Mason's circuit is shown in figure 7.

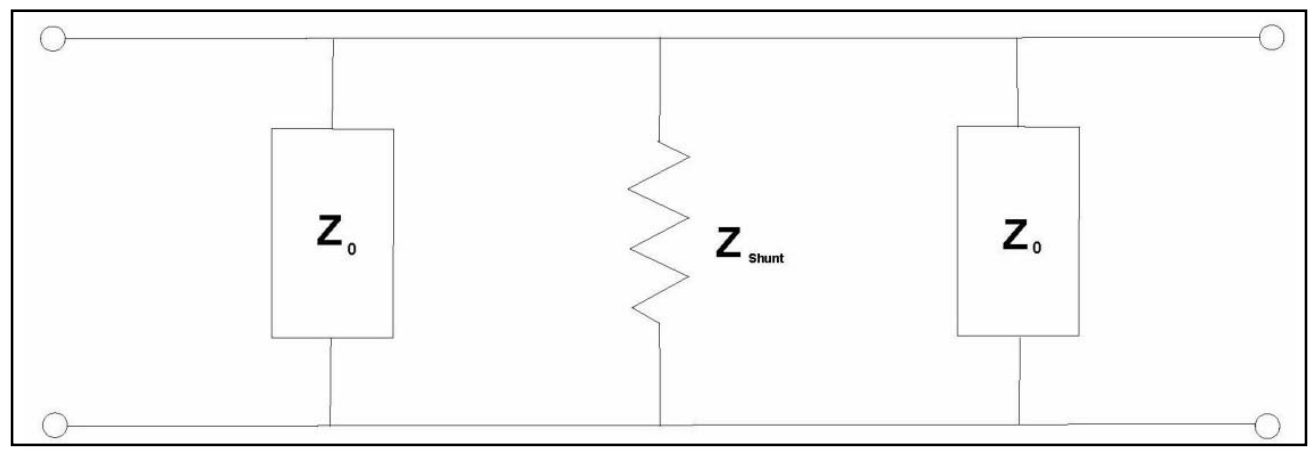

Figure 7. Mason's representation of an acoustic filter as an electronic network.

Here, $Z_{\text {shunt }}$ represents the impedance of the side branch; it could contain several components. $Z_{0}$ is the characteristic impedance of the transmission line leading up to and away from the side branch. In Mason's case, these were lumped components. This circuit is very similar to that which is still described today by modern researchers. For this reason, I am including it here for historical perspective. Later in the analysis section, I will use one of Mason's structures, shown in figure 8 , number 3 , and his equations for equivalent length and area to calculate the resonant frequency of one of our photo-acoustic cells. Mason suggests that the shunt impedance in figure 
7 should contain three elements in a T or $\pi$ configuration. This is exactly what Keefe (17) suggests, and is in fact the circuit that I have chosen to use in my analysis.

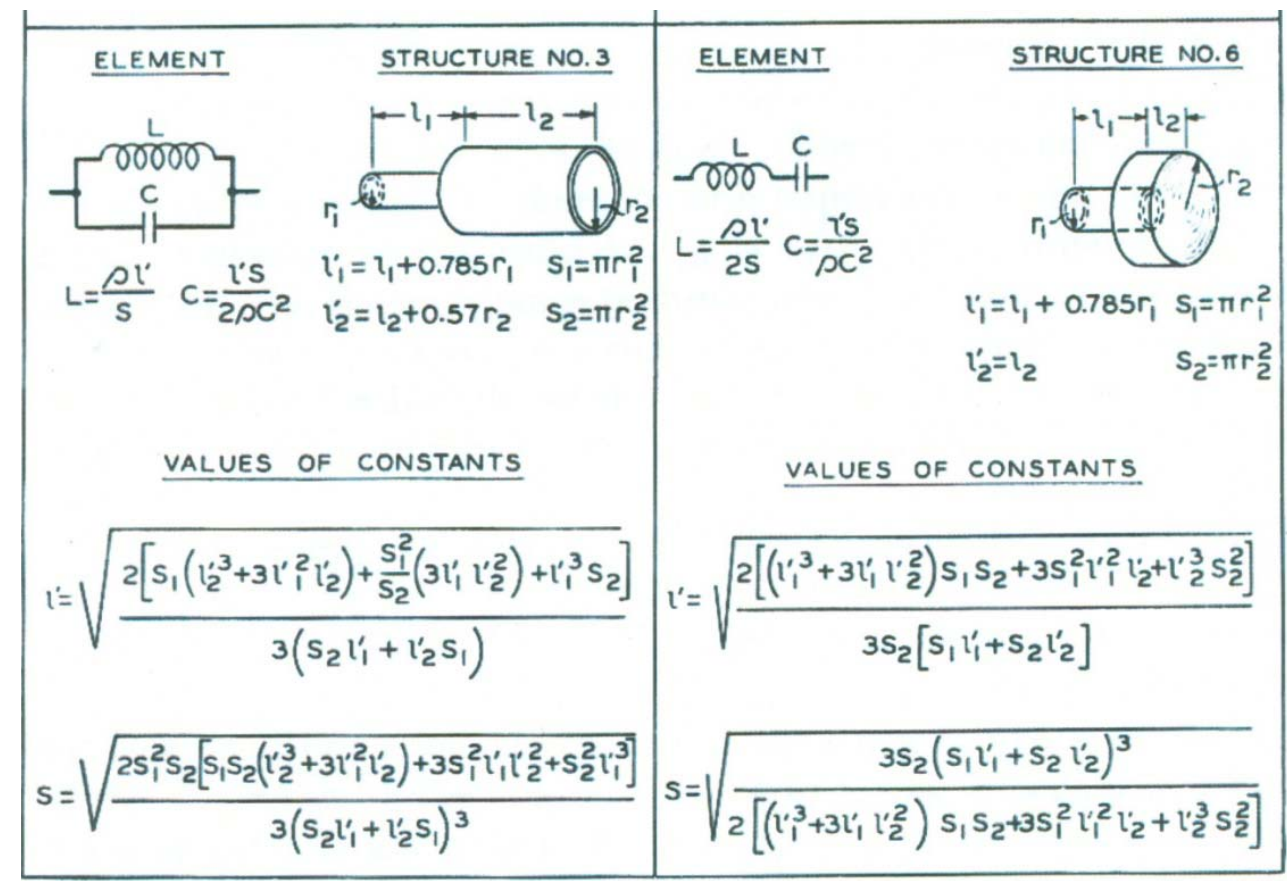

Figure 8. Mason's equivalent for side branch representation.

\section{Experimental Results and Analysis}

Two experiments were performed. The first was initiated, because we were trying to understand the resonant frequency of the photo-acoustic cell in our photo-acoustic spectrometer. The performance of the cell during regular operation always seemed to have a resonance above the calculated value. There were two reasons for this. First, it is very difficult to measure the speed of sound in the cell. In section 2, a method of calculation was offered that yields a value of $335 \mathrm{~m} / \mathrm{s}$ in the tube. This is the value I will use in the calculations done for our $1 \times 10 \mathrm{~mm}$ cell. Second, we were not accounting for the length correction due to the side branch.

The first experiment was done to simply replace our cell with a larger version made of PVC pipe. This tube shown in figure 9 is basically a scale model of our smaller photo-acoustic cell. The photo-acoustic spectrometer cell is $10 \mathrm{~mm}$ in length, $1 \mathrm{~mm}$ in diameter. It has a side branch that is $0.5 \mathrm{~mm}$ in diameter and $1 \mathrm{~mm}$ in length. The model cell is $303 \mathrm{~mm}$ long with diameter of $27 \mathrm{~mm}$. The side branch is $20 \mathrm{~mm}$ long with a diameter of $15 \mathrm{~mm}$. 


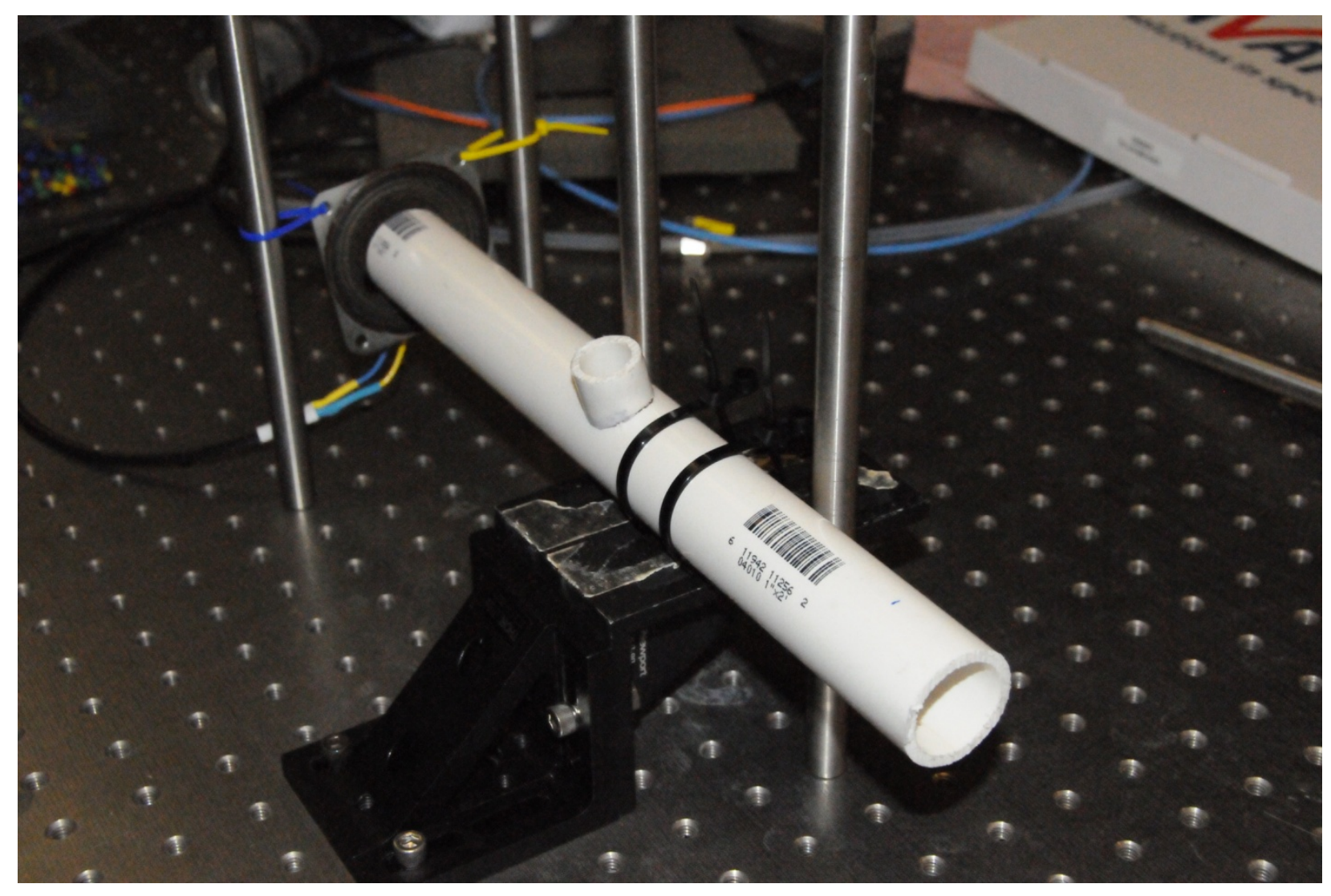

Figure 9. Picture of experimental setup for tube with a single side branch.

The method of analysis is as follows:

$$
\left|\frac{p_{\text {in }}}{U_{\text {in }}}\right|=\left|\begin{array}{cc}
\cos k L & j Z_{0} \sin k L \\
\frac{j}{z_{0}} \sin k L & \cos k L
\end{array}\right|\left|\begin{array}{cc}
1 & 0 \\
\frac{1}{Z_{S}} & 1
\end{array}\right|\left|\begin{array}{cc}
\cos k L & j Z_{0} \sin k L \\
\frac{j}{z_{0}} \sin k L & \cos k L
\end{array}\right|\left|\frac{p_{\text {out }}}{U_{\text {out }}}\right| .
$$

These matrices represent the situation shown in figure 10.

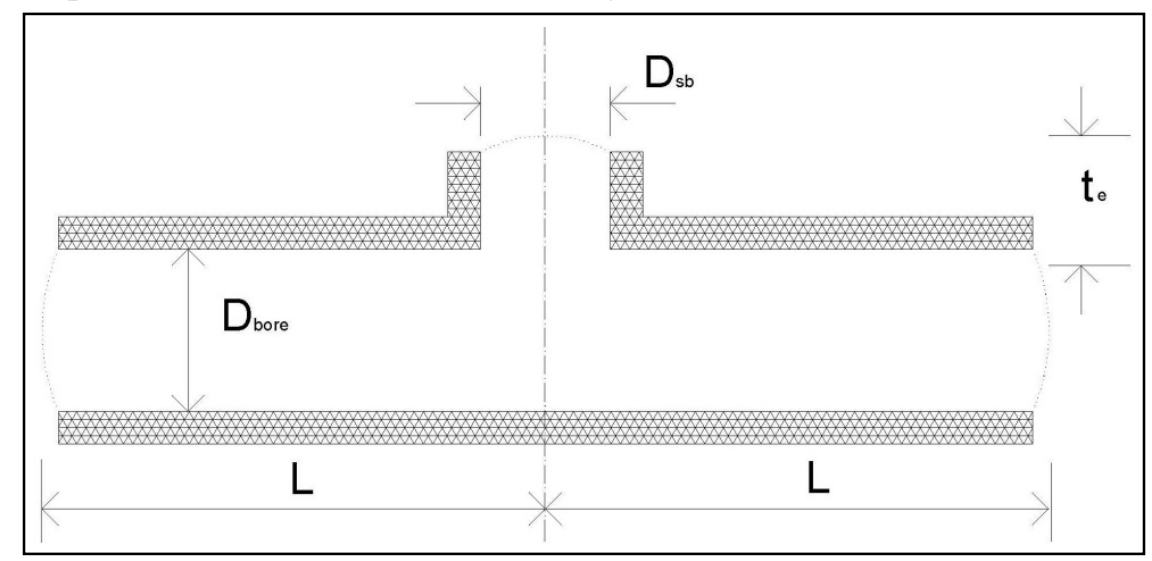

Figure 10. Schematic of the tube shown in figure 9. 
In equation $68, Z_{S}$ is the shunt impedance that represents the side branch. As given in equation 58

$$
Z_{s}=j Z_{0}\left(\frac{D_{\text {bore }}}{D_{s b}}\right)^{2} \tan k t_{e}
$$

The term $\left(\frac{D_{\text {bore }}}{D_{s b}}\right)^{2}$ appears because the characteristic impedance in the side branch is inversely proportional to the area of the side branch, and $Z_{0}$ is inversely proportional to the area of the main tube. After calculating the total matrix for equation 68 and setting $Z_{i n}=\frac{p_{\text {in }}}{U_{\text {in }}}$, we are left with

$$
Z_{\text {in }}=\frac{j Z_{0}\left(\sin 2 k L\left(\frac{D_{\text {bore }}}{D_{s b}}\right)^{2} \tan k t_{e}+(\sin 2 k L)^{2}\right)}{\left(\frac{D_{\text {bore }}}{D_{s b}}\right)^{2} \tan k t_{e}+\sin k L \cos k L}
$$

Now, resonance occurs when the imaginary part of $Z_{\text {in }}$ is equal to zero, so that

$$
\sin 2 k L\left[\left(\frac{D_{\text {bore }}}{D_{s b}}\right)^{2} \tan k t_{e}\right]+(\sin k L)^{2}=0 .
$$

This is the resonance condition. Note the term in the square brackets. This is the input impedance to the side branch. Later, when we analyze side branch structures that are different than the one in figure 10, we can simply calculate the new input impedance to the new structure and substitute it in the square bracket in equation 71.

Now when we insert the dimensions of the PVC model tube into equation 71 and do a numerical analysis, we find that the calculated resonance frequency is $653 \mathrm{~Hz}$. In the test done on the tube in figure 10, the measured resonance was $677 \mathrm{~Hz}$. This is an error of $3.7 \%$. The same analysis was used with substitutions for the dimensions of the $1 \times 10 \mathrm{~mm}$ cell. The calculated resonance was at $18,362 \mathrm{~Hz}$. The measured value of the resonance tested with vinyl acetate as the gas in the cell was $18,500 \mathrm{~Hz}$. This is an error of less than $1 \%$.

A second experiment was performed on the PVC tube in figure 11. We started this test with a tube that had no hole in the side. We tested the resonance frequency of the tube and then drilled holes of various sizes in the side. After each new hole was drilled, the resonance frequency was checked and recorded. The result is shown in table 1. 


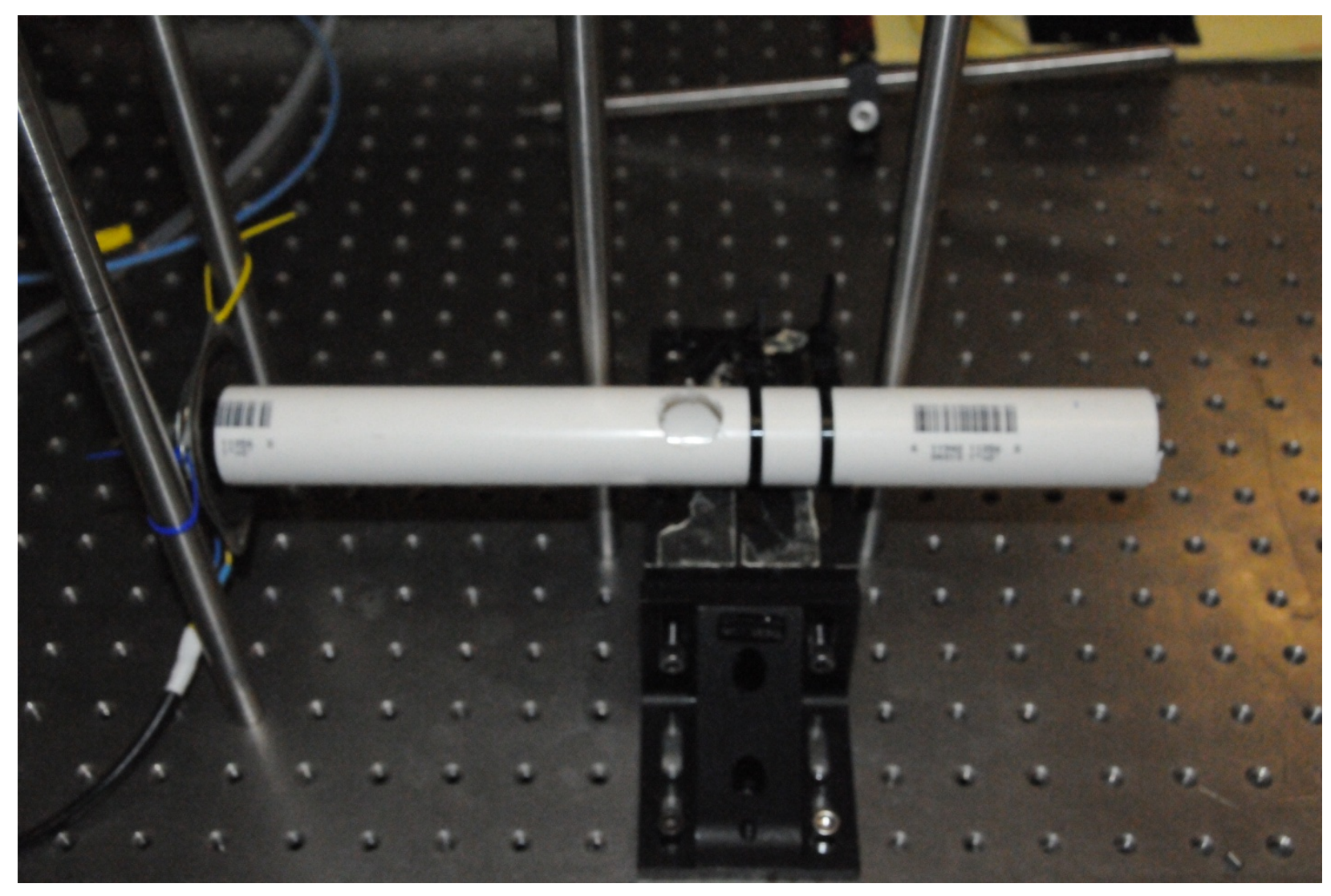

Figure 11. Picture of the tube used for varying the diameter of the side branch.

Table 1. Result of measuring the resonant frequency of tubes with side branches of various diameters.

\begin{tabular}{|c|c|c|c|c|c|c|}
\hline Diameter (m) & $(\mathbf{a} / \mathbf{b})^{\mathbf{2}}$ & $\mathbf{t}_{\mathbf{e}} \mathbf{( m )}$ & $\mathbf{L}_{\text {eff }}(\mathbf{m})$ & $\begin{array}{c}\mathbf{c} / \mathbf{2} \mathbf{L}_{\text {eff }} \\
\mathbf{( H z )}\end{array}$ & $\begin{array}{c}\text { Measured Freq. } \\
\mathbf{( H z )}\end{array}$ & \% Error \\
\hline 0 & - & - & - & - & 517 & - \\
\hline 0.00165 & 248 & 0.004 & 1.146 & 146 & 527 & - \\
\hline 0.00305 & 72.7 & 0.00442 & 0.475 & 352 & 553 & - \\
\hline 0.00561 & 21.5 & 0.00518 & 0.26531 & 630 & 595 & 5.6 \\
\hline 0.0123 & 4.47 & 0.00718 & 0.1861 & 899 & 745 & 17.1 \\
\hline 0.01587 & 2.68 & 0.00826 & 0.17614 & 950 & 783 & 17.6 \\
\hline 0.02222 & 1.27 & 0.01016 & 0.1669 & 1003 & 842 & 16 \\
\hline
\end{tabular}

The most important thing to notice is that the diameter of the side branch hole has a significant effect on the resonant frequency of the tube. Also note that when $(a / b)^{2}>20$, the error is very large. The reason for this is that the effective length of the tube becomes larger than the actual tube, which is $0.308 \mathrm{~m}$. In terms of resonance in the tube, this is not possible.

Now, I turn my attention to the cell shown below in figure 12. This is an actual cell used in a photo- acoustic spectrometer. Note that this structure is different than that shown in figure 10. The microphone chamber is, in effect, a tube with varying diameter. The situation is shown in figure 13 below. The equivalent matrix for this structure is given in equation 72 . 


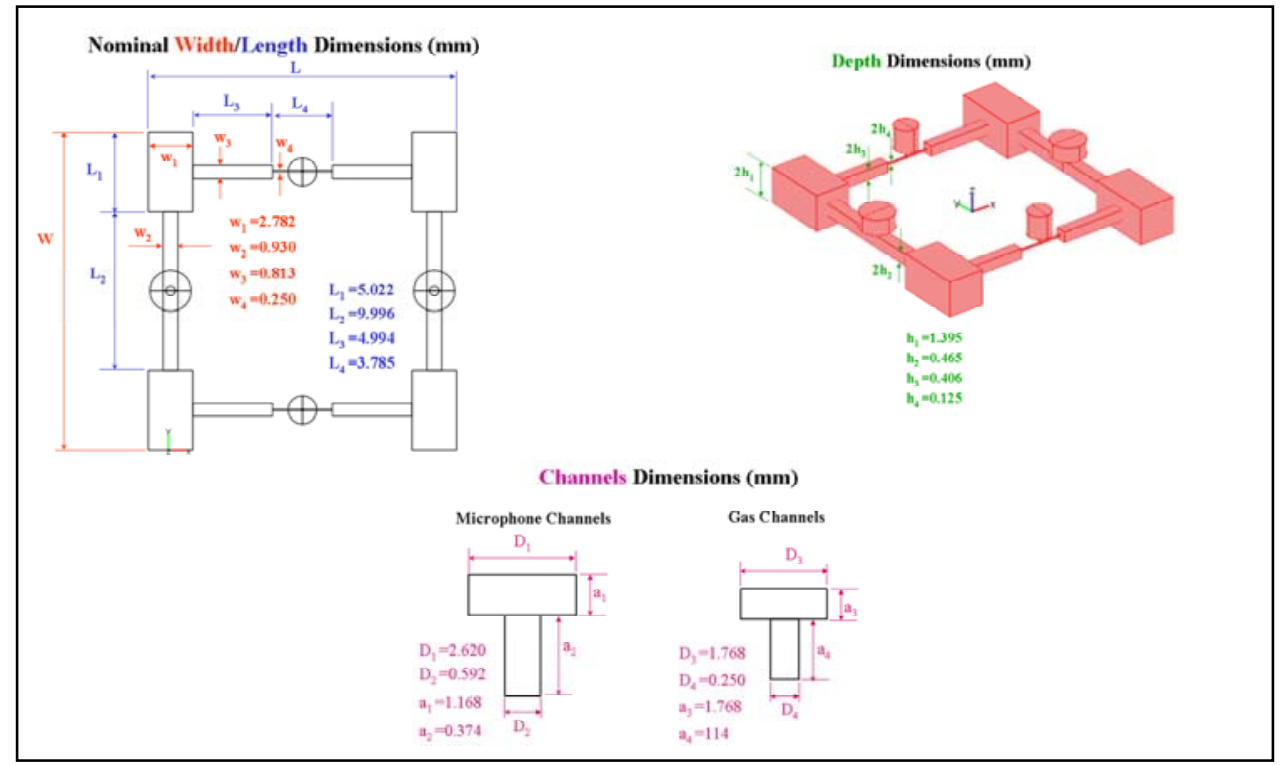

Figure 12. Diagram of actual acousto-optic spectrometer.

$$
\left|\begin{array}{l}
p_{\text {in }} \\
U_{\text {in }}
\end{array}\right|=\left|\begin{array}{cc}
\cos k L_{1} & j Z_{1} \sin k L_{1} \\
\frac{j}{z_{1}} \sin k L_{1} & \cos k L_{1}
\end{array}\right|\left|\begin{array}{cc}
\cos k L_{2} & j Z_{2} \sin k L_{2} \\
\frac{j}{z_{2}} \sin k L_{2} & \cos k L_{2}
\end{array}\right|\left|\begin{array}{l}
p_{\text {out }} \\
U_{\text {out }}
\end{array}\right| .
$$

Here, it should be noted that $Z_{1}=\frac{\rho_{0} c}{S_{1}}=Z_{0}\left(\frac{D_{\text {bore }}}{D_{1}}\right)^{2}$ and $Z_{2}=\frac{\rho_{0} c}{S_{2}}=Z_{0}\left(\frac{D_{\text {bore }}}{D_{2}}\right)^{2}$.

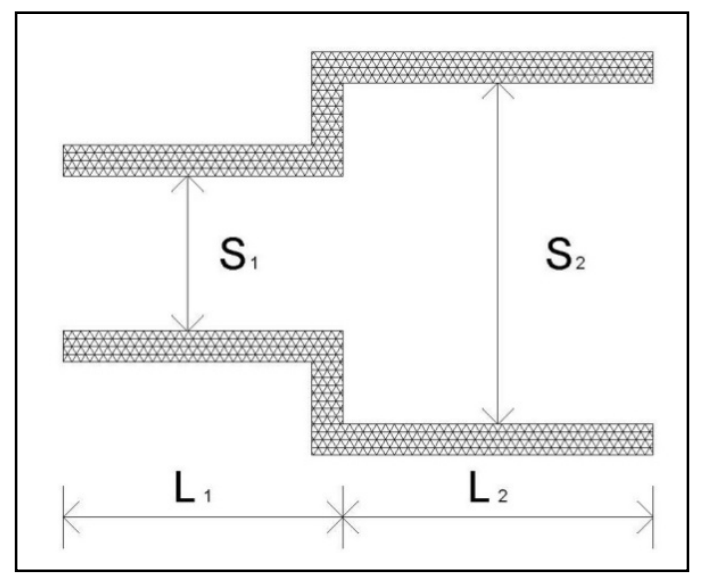

Figure 13. Structure of side branch with two sections.

Using the dimensions given in figure 13 under "Microphone Channels" in equation 72 and solving for the input impedance of the side branch, we find that the imaginary part of $Z_{\text {in }}$ is

$$
\operatorname{Im}\left[Z_{\text {in }}\right]=\left[\frac{\left(\frac{D_{\text {bore }}}{D_{2}}\right)^{2} \sin k L_{2} \cos k L_{1}+\left(\frac{D_{\text {bore }}}{D_{1}}\right)^{2} \sin k L_{1} \cos k L_{2}}{\cos k L_{1} \sin k L_{2}-\left(\frac{D_{2}}{D_{1}}\right)^{2} \sin k L_{1} \cos k L_{2}}\right] .
$$


By inserting this term into the bracketed portion of equation 71 and solving, we are led to a resonance frequency of $20,235 \mathrm{~Hz}$. The measured resonance frequency was $19,800 \mathrm{~Hz}$, so that the error is $2.1 \%$.

I mentioned earlier that there would be a discussion of the sources of error in our calculations. One source of error found in the experiment with varying side branch diameters is the imperfection of the drilled holes. The sharpness of the edges does have an effect on the impedance of the hole. In our case, one can see from figure 12 that the hole is very ragged. Another source of error comes from our assumption that the ends of the tubes are an infinite open with no flange structure. This is not the case in any of the situations discussed. The final source of error to be discussed here is the speed of sound in the tube. In all cases, we assumed perfectly rigid and perfectly smooth sides on the tube. Obviously this can't be the case. We could and have assumed that the formula given at the end of section 2.1 is valid, but in the case of our PVC tube this does not seem to hold true. In that case, the speed was measured to be $334 \mathrm{~m} / \mathrm{s}$, but this measurement was dependant on the assumption that the end correction was $0.3 D$. The calculated value from equation 16 is $338.76 \mathrm{~m} / \mathrm{s}$.

\section{Conclusions}

We have shown that it is quite reasonable to assume that in our photo-acoustic cells the acoustic waves travel as plane waves. This assumption is also supported by Tijdeman (5), where he shows that the velocity profile of waves that a have $S$ (shunt wave number) greater than 10 are fairly flat across area of the tube. In our case of a 1-mm-diameter representative cell, $S=44$, which corresponds to a velocity profile that is very flat across the area of the tube. We developed a matrix method of calculating the input impedance of the acoustic resonators, and using this can predict the resonant frequencies within a few percent. This method can be extended to more complex structures for side branches with similar results. We also showed that the diameter of the side branch hole is critical in the design of a photo-acoustic resonant cell. For side branch diameters that are less than one-quarter the diameter of the main bore the resonant frequency cannot be predicted. 


\section{References}

1. Mason, W. P. The Approximate Networks of Acoustic Filters. Bell System Technical Journal 1930, 9 (2), 332-340.

2. Riensta, S. W.; Hirschberg, A. An Introduction to Acoustics. revised version of IWDE 92-06 Jan 2012 found at http://www.win.tue.nl/ sjoerdr/.

3. Kinsler, L. E.; Frey, A. R. Fundamentals of Acoustics; Wiley, NY, 1962; 108-113, 201-202.

4. Helmholtz, H. V. Verhandlungen der Naturhistorisch-Medizinischen Vereins zu Heidelberg. 1863, $3,16$.

5. Kirchhoff, G. Ueber den Einfluss der Wärmeleitung in einem Gase auf die Schallbewegung. Poggendorfer Annalen 1863, 134, 177-193.

6. Lord Rayleigh. The Theory of Sound Volume II; The Macmillan Company, London, 1896; 319-326.

7. Zwikker, C.; Kosten, C. Sound Absorbing Materials; Elsvier, Amsterdam, 1949; Chpt. 2.

8. Tijdeman, H. On the Propagation of Sound Waves in Cylindrical Tubes. Journal of Sound and Vibration 1975, 39 (1), 1-33.

9. Pozar, D. M. Microwave Engineering; Wiley, NY, 1998; 132-133.

10. Powers, D. L. Boundary Value Problems and Partial Differential Equations; Elsevier, Burlington, MA, 1987; 312-329.

11. Rossing, T. D.; Fletcher, N. H. Principles of Vibration and Sound; Springer-Verlag, NY, 2004; 175-178.

12. Staelin, D. H.; Morgenthaler, A. W.; Kong, J. A. Electromagnetic Waves; Prentice-Hall, NJ, 1994; 220-233.

13. Forster, C. Musical Mathematics: On the Art and Science of Acoustic Instruments; Chronicle Books, San Francisco, CA, 2010; Chpt. 8.

14. Nederveen, C. J. Acoustical Aspects of Woodwind Instruments; Northern Illinois University Press, DeKalb, IL, 1998; 11-14, 45-49.

15. Stewart, G. W. Acoustic Wave Filters. Physical Review 1922, 20 (6), 528-551.

16. Stewart, G. W. Acoustic Wave Filters: An Extension of the Theory. Physical Review 1925, 25 (1), 90-98.

17. Keefe, D. H. Experiments on a Single Woodwind Tone Hole. Journal of the Acoustical Society of America 1982, 72 (3), 688-699. 


\section{List of Symbols, Abbreviations, and Acronyms}

$x \quad$ equilibrium coordinate of a thin sheet of molecules

$\xi \quad$ displacement of the sheet along the axis of propagation

$u \quad$ velocity of the sheet $u=\frac{\partial \xi}{\partial t}$

$\rho \quad$ instantaneous density at any point

$\rho_{0} \quad$ constant equilibrium density of the medium

$s \quad$ condensation at any point defined as $s=\frac{\rho-\rho_{0}}{\rho_{0}}$ or $\rho=\rho_{0}(1+s)$

$P \quad$ instantaneous pressure at any point

$P_{0} \quad$ constant equilibrium pressure

$p \quad$ excess pressure or acoustic pressure at any point defined as $p=P-P_{0}$

$c \quad$ velocity of wave propagation

$v_{p} \quad$ phase velocity

$\Gamma \quad$ propagation constant in Zwikker-Kosten derivation of phase velocity

$\Gamma_{L} \quad$ reflection coefficient at the load of a transmission line

$\delta_{A} \quad$ thermal boundary-layer thickness

$v \quad$ kinetic viscosity

$\eta \quad$ dynamic viscosity

$\gamma \quad$ ratio of the specific heats

$C_{V} \quad$ specific heat at constant volume

$C_{P} \quad$ specific heat at constant pressure

$k$ propagation constant everywhere except velocity calculation

$r \quad$ radius of the tube

$D \quad$ diameter of the tube

$z \quad$ propagation direction

$\omega \quad$ radian frequency 
$L \quad$ length in tube

Z impedance

$Y \quad$ admittance

Voltage

I current

$t_{e} \quad$ effective length of a side branch

$\lambda_{b} \quad$ effective length of a side branch corrected for the diameter of the main tube 


\begin{tabular}{|c|c|}
\hline $\begin{array}{l}\text { NO. OF } \\
\text { COPIES }\end{array}$ & ORGANIZATION \\
\hline $\begin{array}{c}1 \\
(\mathrm{PDF})\end{array}$ & $\begin{array}{l}\text { DEFENSE TECHNICAL } \\
\text { INFORMATION CTR } \\
\text { DTIC OCA }\end{array}$ \\
\hline $\begin{array}{c}1 \\
(\mathrm{PDF})\end{array}$ & $\begin{array}{l}\text { DIRECTOR } \\
\text { US ARMY RESEARCH LAB } \\
\text { RDRL CIO LL }\end{array}$ \\
\hline $\begin{array}{c}1 \\
\text { (PDF) }\end{array}$ & $\begin{array}{l}\text { GOVT PRINTG OFC } \\
\text { A MALHOTRA }\end{array}$ \\
\hline $\begin{array}{c}1 \\
(\mathrm{PDF})\end{array}$ & $\begin{array}{l}\text { DIRECTOR } \\
\text { US ARMY RESEARCH LAB } \\
\text { ATTN RDRL SEE E } \\
\text { J SCHILL }\end{array}$ \\
\hline
\end{tabular}

